\title{
DE LOS BIENES DE JUDÍOS, ¿QUÉ SE HIZO?
}

PILAR LEÓN TELLO

Archivo Histórico Nacional. Madrid

Terminada la reconquista de Granada, emprenden los Reyes Católicos las grandes reformas que necesitaba el país, en un momento crucial entre el fin del medievalismo y la creación de un nuevo estado.

Uno de los problemas más acuciantes que había que resolver era la represión de la apostasía, muy extendida entre los conversos; databa la existencia de éstos en gran escala, desde el trágico movimiento antisemita de 1391, que causó la pérdida de tantas vidas y bienes de judíos; gran número de ellos se hicieron entonces cristianos por conservarlos, aunque siguieron guardando en su interior su fe religiosa.

Para reprimir la herejía de los judaizantes, ordenaron los reyes en 1480 que vivieran los judíos en barrios apartados, con el fin de evitar su influencia sobre los conversos; impulsaron el establecimiento del tribunal de la Inquisición y decretaron, tres años más tarde, la expulsión parcial de los judíos de Andalucía.

Ninguna de estas medidas dio resultado; era muy difícil desarraigar de los convertidos la religión de sus antepasados, por el continuo trato con sus familiares y amigos judíos. El historiador Hernando del Pulgar, al tratar de este problema, dice que dentro de una misma casa había diversidad de creencias y se "encubrían" los unos de los otros '. Tampoco en el interior de las aljamas reinaba mucha tranquilidad, según escribe Yosef ha-Kohen:

"También la mano de Yahveh estuvo contra ellos para desconcertarlos, y se acometían entre sí, el hombre a su amigo, el niño al anciano y el vil al honorable. Cuando pedía una mujer a su vecina

'H. DEL Pulgar, Crónica de los Setiores Reyes Católicos, don Fernando y dotia Isabel de Castilla y Aragón, Madrid 1878, BAE tomo 70, págs. 223-773, 432. 
o a una prosélita de su casa, utensilios de plata o de oro y no se los daba, iba a denunciarlas. Sintieron hastío de sus vidas en aquella época" ${ }^{2}$.

Para poner fin a esta disgregación interna, recurrieron los reyes, "tras mucha deliberación y consejo", a la supresión tajante del judaísmo, decisión que parecía inevitable; según el criterio de la época, la unidad religiosa era algo imprescindible para la integridad moral de un pueblo, y la consecución de este fin, anularía el sentimiento de la pérdida de bienes que el destierro de los judíos pudiera ocasionar.

El edicto de expulsión, fechado el 31 de marzo de 1492, no se hizo público hasta los últimos días de abril.

Judíos con importantes cargos en la administración del reino intentaron, con ofrecimiento de aportaciones económicas, disuadir a los reyes de llevar a cabo la ejecución del edicto; entre ellos, como más allegados a la corte, destacaba Abraham Seneor, recaudador mayor de impuestos, tesorero de la Santa Hermandad, y rab y juez mayor de los judíos; Abraham y su yerno Meir Melamed recibieron el bautismo poco antes del término señalado para el éxodo. Otro personaje influyente, Işhaq Abravanel, y un familiar suyo, Yuçaf, que tenían el arrendamiento de gran parte de las rentas reales, optaron por el destierro.

Los judíos, que tenían de plazo hasta el 31 de julio para disponer su salida, quedaban bajo la protección de los reyes y se les autorizaba a vender o cambiar sus bienes, permitiéndoles que los llevaran consigo, siempre que no fueran oro, plata, monedas, armas y caballos, que las leyes generales prohibían sacar del reino.

Los problemas económicos que se originaron tras la publicación del edicto de expulsión fueron incalculables. Los comerciantes, cambistas y arrendadores de rentas tenían muchas cantidades pendientes de cobro o pago; deudas y préstamos daban lugar a reclamaciones de créditos y fianzas, de difícil solución en corto plazo.

Los judíos más acaudalados, con el asesoramiento de notarios y juristas, se dispusieron a liquidar sus bienes con el menor perjuicio posible y se apresuraron a vender sus haciendas, a otorgar poderes para realizar operaciones financieras, o a dar sus propiedades a

${ }^{2}$ Y. HA-KoHen, El Valle del Llanto ('Emeq ha-Bakha), Introd. trad. y notas por P. León Tello, Barcelona 1989, pág. 118. 
amigos suyos cristianos, probablemente, a cambio de ayuda; podemos citar al físico Simuel Abenxuxen que deja sus numerosas casas, censales y cuantos bienes poseía en el castillo de Huete, a su señor el marqués de Villena, en agradecimiento a las buenas obras que de él había recibido ${ }^{3}$.

Los menos afortunados cambiaban sus posesiones por asnos, bueyes o carretas que iban a necesitar durante el viaje. Muchos judíos burgaleses y de la zona del Duero acudían a negociar sus mercancías a la feria que se celebraba en mayo en Medina del Campo.

Los reyes nombraron comisionados especiales para que valorasen los bienes de los hebreos e intervinieran en toda clase de conflictos de índole económica; pero como todo pueblo en desgracia, tuvieron los judíos que soportar no pocos abusos. Municipios y particulares conseguían eximirse del pago de préstamos de judíos, acusándolos de usura y fraude en los contratos; incluso algunos receptores y depositarios encargados de vigilar las transacciones, aprovechando el vacío administrativo y jurídico que se produjo, cometían a su vez una serie de tropelías, y hasta los reyes llegaban denuncias de todo tipo. No sería, sin duda, un caso aislado la conducta del corregidor de León, Juan de Portugal, a quien acusaba el regidor de haber recibido de la aljama de la ciudad $30.000 \mathrm{mrs}$. con la promesa de protegerla y agilizar el cobro de deudas y ventas, de ejecutar cualquier demanda contra los judíos sin previa investigación, y de quedarse con las prendas que le entregaban los judíos para garantizar el pago de sus compras; su casa, según el munícipe, estaba llena de muebles, joyas y ropas que retenía sin derecho ${ }^{4}$.

Se prohibió la venta de las sinagogas por haber estado destinadas al servicio de Dios; la de los osarios hebreos, por ser también lugares sagrados, y la de los bienes comunes de las aljamas, que al no tener un dueño personal, correspondían a la Corona. Iglesias, monasterios y cofradías fueron los principales beneficiarios en la concesión de las sinagogas y sus destinos fueron muy variados. Podemos aducir como ejemplos: la sinagoga de Salamanca, donde el cabildo construyó casas para venderlas más tarde; los materiales de la sinagoga de Calahorra sirvieron para edificar una iglesia; la

\footnotetext{
${ }^{3}$ P. León Tello, Judios de Toledo, tomo I, Madrid 1979, págs. 543-546.

${ }^{4}$ L. SuÁrez Fernández, Documentos acerca de la expulsión de los judlos, Valladolid 1964, págs. 442-443.
} 
toledana de Simuel Leví fue concedida por los reyes a la orden de Calatrava, no sin protesta de la parroquia de Santo Tomé en cuya demarcación se encontraba; en Trujillo el concejo reclama para iglesia la sinagoga que los reyes habían dado al prior dominico de la Encarnación para construir un convento donde se recogieran las monjas de su orden; en Pastrana, los judíos concertaron ellos mismos con el guardián y frailes del monasterio de Santa María de Gracia la concesión de su sinagoga con los corrales adyacentes, en compensación de una deuda. Entre las cofradías a las que fueron concedidas sinagogas, podemos citar la de la Pasión de Castro del Río, que había de servir para transformarla en hospital que acogiese a pobres y enfermos, y la cofradía de la Trinidad de Sahagún que se encargaría de atender a romeros.

Algunas sinagogas fueron concedidas a concejos, como la palentina; no encontrando el corregidor ninguna cofradía que se hiciere cargo de ella para hospital, fue puesta en subasta pública y rematada en dos carniceros moros que edificaron en ella un matadero.

Los osarios figuraban por lo común en las escrituras de donación de sinagogas, adjudicándose las piedras a edificios eclesiásticos y dejando los solares para aprovechamiento público concejil; podemos resaltar el acuerdo que adoptó el 27 de junio de 1492 la aljama de Vitoria, concediendo al ayuntamiento de la ciudad el campo de su cementerio, el Judizmendi, con la condición de que no fuera dedicado a labores agrícolas, sino a aprovechamiento de su dehesa; este acuerdo se mantuvo durante siglos, hasta que en 1952 una delegación de la comunidad hebrea de Bayona eximió a Vitoria de su antiguo compromiso.

En cuanto a los bienes comunes de las aljamas, enviaron los reyes a personas de su confianza a las distintas poblaciones, para que averiguasen las casas, tierras y censos que debían adjudicarse al fisco.

También los nobles se apresuraron a informarse de los bienes que poseían los judíos en las tierras de sus señorios, ya que, en gran parte, pasarían a ser de su propiedad por concesión regia y en compensación de la pérdida de rentas y vasallos.

Se conservan inventarios de bienes hechos en 1492 en algunas ciudades, que nos informan del número de propietarios judíos que las habitaban, de sus bienes rústicos y urbanos, y del valor de los mismos. 
Algunos de estos inventarios se han publicado y pueden servir como ejemplo orientativo de las pertenencias judaicas en aquellos momentos. Sabemos que en Buitrago había cerca de un centenar de judíos más o menos ricos que poseían en conjunto 55 casas intramuros y 31 en el arrabal, un horno, una tenería, dos sinagogas, un hospital, carnicería y osario propios; la hacienda rural comprendía 160 linares, 118 prados, 26 huertas y 170 fanegas de tierra. Todo ello tenía un valor en venta de $809.360 \mathrm{mrs}$. y en renta, 34.895 mrs. s.

En Hita habitaban más de 120 judíos que eran dueños, entre todos, de 109 casas, 4 tiendas, 4 palomares, 5 corrales y 2 molinos; y como bienes rústicos poseían 396 viñas, 34 pedazos de tierra, 12 olivares, 19 membrillares y algunos pinos, guindos y cerezos. Figuran también en el inventario dos sinagogas, un midrás, el osario y el muladar judío ${ }^{\text {. }}$

De San Martín de Valdeiglesias se relacionan 130 casas, más casillas y solares, además de la sinagoga, osario y carnicería propia; en un segundo inventario aparecen casi medio centenar de casas, 5 corrales y 2 pajares pertenecientes a 40 dueños; y como riqueza rural, contaban con 150 viñedos, 9 huertas, 1 linar y 2 majadas, repartidos entre 80 propietarios?.

Buitrago, Hita y San Martín de Valdeiglesias pertenecían al señorío del duque del Infantado y gran parte de sus documentos se conservan en la Sección de Osuna del Archivo Histórico Nacional.

Otro inventario similar, aunque más completo, se hizo en la población toledana de Maqueda, que correspondía al señorío del comendador de León, Gutierre de Cárdenas. Constaba allí la existencia de 281 familias judías poseedoras de bienes, frente a medio centenar de cristianos pecheros; cuando se promulgó la orden de destierro, doña Teresa Enríquez, mujer del comendador Cárdenas, envió unos jueces y oidores a que residiesen continuamente en Maqueda con el fin de que resolvieran las deudas, pleitos y causas que originasen la evaluación de posesiones hebraicas. En más de $\mathbf{3 0}$

${ }^{5}$ F. Cantera Burgos y C. Carrete Parrondo, "La Judería de Buitrago», Sefarad XXXII (1972) 3-87.

'F. Cantera Burgos y C. Carrete Parrondo, "La Judería de Hita", Sefarad XXXII (1972) 249-305.

7 F. Cantera Burgos, «La judería de San Martín de Valdeiglesias (Madrid)», Sefarad XXIX (1969) 217-312. 
pliegos se inserta un «Registro y relación de bienes raíces» de todo judío vecino de la villa, haciendo constar las heredades de viñas, olivos, zumaques, huertas, tierras, molinos y casas que pertenecían a cada uno; otros pliegos titulados "Forasteros", incluyen los nombres de 28 foráneos que habían acudido a Maqueda a comprar casas de judíos; en pliegos de "Acreedores" se registran otras 71 casas que los hebreos habían tenido que entregar para saneamiento de deudas o tributos; y por último, los pliegos más interesantes son los de "Ventas" realizadas ante distintos escribanos; figuran en ellos los nombres de los judíos vendedores y de los cristianos adquirentes, los nombres y linderos topográficos de las fincas y el valor de las mismas. El precio de las casas vendidas asciende a $80.890 \mathrm{mrs}$., 654 reales, una dobla castellana, tres vacas, una novilla y un borrico; una sola casa podía valer 15 reales, más un asno de 40 reales y un capuz de 21; los olivos en total se apreciaron en $61.620 \mathrm{mrs}$.; las viñas, en $26.165 \mathrm{mrs}$. y 288 reales; las tierras, en $5.800 \mathrm{mrs}$. y 43 reales; el hospital y el baño de los judíos se vendieron en 20 y 15 reales respectivamente, $y$ otras pequeñas cantidades se pagaron por tiendas, corrales, una huerta, una bodega y un zumacal ${ }^{8}$.

Gran parte de los bienes de los judíos que marcharon al destierro fueron a parar a manos de banqueros genoveses que les facilitaban letras de cambio, o a patrones y capitanes de navíos, con quienes concertaban su transporte; otros, les fueron robados por los caminos terrestres o marítimos.

Se fueron los judíos a finales del mes de julio, «adonde los empujaba el viento".

De Cádiz partieron en 25 naves al mando del capitán Pedro Cabrón, con destino al norte de Africa. En Fez consiguieron establecer una improvisada judería con casas de paja, que un gran incendio se encargó de destruir; en Arcila recibieron muchos el baustismo y volvieron a la península.

Dieciséis grandes naves salieron de Cartagena hacia Italia, llegando sus pasajeros tan maltrechos a Genóva, que testigos presenciales aseguraban que parecían espectros '. En otros lugares de Italia fueron bien recibidos: el duque de Ferrara, Hércules de Este,

${ }^{8}$ P. LEÓn Tello, Judíos de Toledo, tomo II, págs. 549-607.

9 B. De Senarega, «De rebus genuensibus», en D. M. MURATORI, Rerum italicarum scriptores praecipui ab anno 500 ad annum 1500, 1723-1738, vol. XXIV, págs. 531-552. 
acogió en su ducado a veintiuna familias judías ${ }^{10}$, y en Nápoles, Fernando I hace extensivos los privilegios que tenían los judíos residentes en el país, a los procedentes de España; entre ellos, arribaron Yşhaq y Yuçaf Abravanel, cargados de riquezas, pues excepcionalmente los Reyes Católicos los habían autorizado a sacar mil ducados de oro a cada uno y joyas de oro y plata, como compensación de las cantidades del arrendamiento de impuestos que no habían podido recaudar ".

Muchos hebreos de la costa levantina se fueron por mar a ciudades meridionales de Francia, y la escasa población judía del norte embarcó en Laredo o en La Coruña, con diversos rumbos.

Los más afortunados llegaron a Salónica y Turquía, donde hallaron la mejor de las acogidas; allí han permanecido y prosperado hasta alcanzar muy altas cotas, pero conservando sus peculiaridades culturales, nuestra lengua y costumbres; son los sefardíes orientales que tantas afecciones y simpatías despiertan en todos nosotros.

El principal refugio para la gran mayoría del pueblo judeoespañol fue sin duda Portugal, como nación más cercana. Los hijos de Abraham Bienveniste el Viejo negociaron con el rey Juan II la entrada de judíos en su país y se permitió el pase de 600 familias mediante el pago de dos escudos de oro por cabeza, aunque fueron muchos más los que pasaron clandestinamente la frontera a pie y por caminos desviados. Cuatro años más tarde fueron también desterrados de ese reino por Manuel I.

Es de notar que durante estos tres meses, últimos de su residencia en nuestro país, no se registra ningún movimiento de protesta por parte de los expulsados; únicamente se produjo en Huete un breve alboroto nocturno a principios de mayo contra los conversos, a quienes muchos achacaban gran parte de responsabilidad en el infortunio que sufrían ${ }^{12}$.

A los judíos que en 1492 no quisieron arrostrar los peligros del exilio se les ofrecía, como única solución, su conversión al cristianismo. Historiadores hebreos de la época nos informan de que miles de judíos, así potentados como gente humilde, eligieron quedarse en

${ }^{10}$ L. Modona, «Les exiltes d'Espagne à Ferraréw, Revue des Études Juives XV (1887) 117-121.

$"$ N. Ferorelli, Gli ebrei nell'Italia Meridionale, Turín 1915, págs. 78-88.

12 L. SuÁrez Fernández, Documentos, págs. 401-402. 
sus casas aun a costa de abjurar de su ley ${ }^{13}$. Algunos vacilaban a punto de abandonar Castilla, como un judío de Atienza, que en Ciudad Rodrigo recibió el baustismo junto a su mujer, hijos y parientes, que sumaban cincuenta y tres familiares.

Fueron muchos también los que, después de soportar las penalidades del destierro, a los pocos meses deseaban volver a España; el 10 de noviembre de 1492, los reyes concedieron un seguro a los refugiados en Portugal ${ }^{14}$, extensivo más tarde a los de Navarra y otros, amparando a las personas y bienes de los judíos que quisieran retornar a nuestro país, con la condición de que se hubieren bautizado o lo hicieran en los puestos fronterizos en presencia de las autoridades eclesiásticas y civiles.

Por lo general, los que regresaban eran bien recibidos, especialmente profesionales, como médicos; consta la intervención, nada menos que del cardenal de España, para que se autorizase al físico Çag Abuacar a venir libremente y traer consigo sus libros, incluso los escritos en árabe o hebreo, siempre que no se tratase del Talmud ni de otras obras de la ley mosaica. También los madrileños testimonian su benevolencia hacia los físicos judíos; en los libros de Acuerdos del Ayuntamiento anotan los regidores que habían asignado nuevamente salario a los médicos que habían vuelto convertidos,

"pues todos eran buenos físicos y no se deve dar lugar a que se vayan, pues toda la villa por sus petiçiones lo an pedido" ${ }^{15}$.

A los que volvían se les concedia el derecho a recuperar los bienes que vendieron a su salida, previo pago de las cantidades que recibieron al enajenarlos y de las mejoras que en ellos se hubieren realizado posteriormente. Esta medida, que era de justicia, fue de muy difícil aplicación; es comprensible la oposición de los nuevos dueños a devolver unas adquisiciones que, a veces, les costó la venta de sus propios bienes. Los mismos reyes habían dispuesto ya de gran parte de las haciendas que dejaron los judios para fines que también eran justos, como el compensar con ellos las pérdidas que

13 "R. Abraham of Torrutiel's Supplement", en A. Neubauer (ed.), Mediaeval Jewish Chronicles and Chronological Notes, vol. I, Oxford 1887, págs. 111-112.

14 L. SuÁrez Fernández, Documentos, págs. 487-489.

is A. Gómez Iglesias, Libro de Acuerdos del Concejo Madrileño, tomo III, Madrid 1970, pág. 69. 
hubieren experimentado las personas que habían tenido cantidades y juros situados en rentas de la carnicería y del vino judiegos, o en el servicio y cabeza del pecho de los judíos. Se presentaban reclamaciones muy particulares; la catedral de Segovia alegaba que había dejado de percibir los treinta mrs. que cobraba de todos los judíos censados, en memoria de los treinta dineros que cobró Judas por entregar al Señor; las casas de unos judíos de Sevilla que se ausentaron sirvieron de recompensa a un correo de la ciudad que "por dos vezes avés venido con la nueva de las caravelas de las Indias»; otros bienes eran irreversibles, como unas esclavas blancas que había dejado un judío de Murcia a un vecino de Toledo. Los concejos vieron disminuir sensiblemente los tributos con la marcha de los judíos; alguno, como el de Iriépal, pretendía anular las ventas que hicieron los judíos de tierras y olivares a familias no pecheras.

Los alcaldes de corte eran los encargados de resolver las apelaciones.

Los bienes judaicos más conflictivos fueron las deudas, hasta el punto de que los reyes dieron una disposición en Zaragoza, el 10 de septiembre de 1492 , ordenando que no se pagase ninguna deuda ni se ejecutasen contratos de judíos anteriores a 1492, hasta que se viera este asunto en el Consejo Real; fueron muchos los cristianos afectados, y el 26 de febrero de 1493 hubo de levantarse el embargo de deudas.

Muchos bienes judaicos fueron confiscados por los inquisidores como castigo al delito de herejía, que no acababa de ser extirpada.

En los primeros años de actuación del Tribunal del Santo Oficio, los reconciliados que habían estado sentenciados a la pena capital o a cárcel perpetua eran condenados a confiscación de bienes y se les declaraba inhábiles para el ejercicio de cargos públicos, tanto a ellos como a sus descendientes hasta la tercera generación. Cuando la culpa era menos grave, se imponía a los infractores penas arbitrarias o se les sometía a ciertos actos penitenciales como la asistencia a procesiones o la obligación de llevar sambenitos. Los bienes confiscados se vendían, por lo general, en pública subasta y servían para cubrir gastos extraordinarios y salarios de los inquisidores, para atender a la guerra de Granada o a la construcción de Santa Fe. Con sumas de la misma procedencia se pagaba asimismo, esporádicamente, sueldos atrasados o ayudas de costa de algunos oficiales 
reales, como camareros, continos alcaides, tesoreros, reposteros de estrados, ballesteros de caza y otros oficios de diversa categoría.

En la nueva etapa, tras el 92 , aún era grande el número de criptojudíos, a pesar de que, para apartarlos de sus prácticas y costumbres, los reyes habían dispuesto que los conversos vivieran separados unos de otros, entre antiguos cristianos y fuera de sus juderías, las cuales habían quedado despobladas en muchas ciudades.

Con el fin de atraerlos pronto a una vida en común con los cristianos, se permitió a los conversos que recuperaran sus bienes raíces confiscados, haciendo "iguala" o "composición" con los receptores del Santo Oficio y mediante el pago de una determinada cantidad. Otra modalidad, las "conmutaciones", se concedían a grupos, o a los habitantes conversos de una población, y consistían en sanciones pecuniarias que los eximía de penitencias y señales infamantes.

En los años 1495 a 1497, la aplicación de otro procedimiento, las llamadas "habilitaciones", dio lugar al avance definitivo en la incorporación de judeoconversos a la sociedad hispana; los reconciliados y los hijos y nietos de condenados, pagando un porcentaje de sus bienes a los inquisidores, que solía ser de $5 \%$, podían en adelante disponer libremente de sus bienes y se les consideraba "hábiles" para desempeñar los cargos administrativos de que habían estado desposeídos. Las cuentas presentadas por los promotores fiscales de la Inquisición se conservan, en su mayor parte, en la Contaduría Mayor de Cuentas del Archivo de Simancas; otras, como las relativas al arzobispado de Toledo, se encuentran en el Archivo Histórico Nacional, en las Secciones de Inquisición y en la de Clero, entre los papeles de la catedral toledana. Son relaciones nominales de los conversos de cada arzobispado en las que se expresa el nombre, oficio y filiación de los conversos, solos o con sus familiares, el valor de sus bienes y las cantidades que habían de entregar a los inquisidores por las conmutaciones, penas arbitrarias, penitencias y habilitaciones que se les había impuesto. Estos padrones constituyen una fuente muy valiosa para estudiar la densidad de población judeoconversa en los distintos lugares, su posición económica y actividades.

Se han publicado varias de estas nóminas; especialmente se conocen con detalle las referentes a los conversos andaluces entre 
1488 y $1497^{16}$, y las de judaizantes de Toledo en 1495 y $1497^{17}$; de ellas me voy a limitar a extraer los datos referentes a las capitales de los respectivos arzobispados, aun teniendo en cuenta que el número e importancia de la sociedad conversa en algunas poblaciones superaba al de los residentes en la capital.

En Sevilla, en febrero de 1496, se recaudan 3.024.468 mrs. entre 1.840 personas habilitadas, quedando 150 personas sin habilitar, y otras 23 en abril.

En Huelva, en 1494, se reparten $152.100 \mathrm{mrs}$. entre 30 personas; en febrero de 1496, 41.750 mrs. sin determinar el número de personas, y en abril del mismo año figuran otras tres personas, pero no se expresa cantidad alguna.

En Cádiz, en ènero de 1497, se asignan $17.700 \mathrm{mrs}$. a pagar entre 5 personas.

En Jaén, en 1493, se recaudan 3.288.579 mrs. por penitencias.

En Córdoba, en 1497, se reparten 1.466 .560 mrs. entre 1.589 personas.

En Toledo, en 1495, figura un total de 1.640 conversos a los que se exige la cantidad de $3.553 .200 \mathrm{mrs}$.

En Ciudad Real, en 1497, hay 413.700 mrs. repartidos entre 166 personas.

En Madrid, en 1497, se distribuyen 83.700 mrs. entre 53 personas.

En Guadalajara, en 1497, se reparten 190.000 mrs. entre 109 personas.

El montante de lo recaudado en todo el arzobispado de Toledo se eleva a $6.499 .028 \mathrm{mrs}$., según el finiquito de la cuenta que hizo el promotor fiscal Diego Martínez de Ortega con el tesorero Alonso de Morales. Al número de personas que figuran en las nóminas hay que añadir el de hijos y hermanos menores, que no se especifica.

La distribución de cantidades a pagar es muy irregular, oscila entre los $100 \mathrm{mrs}$. y hasta cerca de $200.000 \mathrm{mrs}$., según la hacienda de los afectados. Éstos, por lo general, son artesanos de diversos oficios: plateros, mercaderes y cambistas, zapateros, curtidores, tejedores, sastres, etc; son escasos los que desempeñan cargos de algún

\footnotetext{
${ }^{16}$ M. A. LADERo QUeSADA, "Judeoconversos andaluces en el siglo XV"I Congreso Internacional Encuentro de las tres culturas, Toledo 1983, págs. 37-68. fDEM, “Los conversos de Córdoba en 1497 "El Olivo XIII (1989) 187-205.

17 F. Cantera Burgos y P. León Tello, Judaizantes del arzobispado de Toledo habilitados por la Inquisición en 1495 y 1497, Madrid 1969.
} 
nivel cultural, como médicos, notarios, escribanos, alguaciles y jurados; los del sector agrícola apenas están representados.

El número de habilitados incluidos en las listas no refleja exactamente la totalidad de conversos; en los libros del Registro General del Sello encontramos bastantes nombres de personas a quienes se han confiscado los bienes por herejía, que no coinciden con los de las nóminas; y hay que tener en cuenta que la acción inquisitorial se extendía sólo contra judaizantes y que otros conversos, por falta de hacienda $u$ otras circunstancias, no considerarian necesario presentarse a las habilitaciones; puede servirnos de ejemplo la judería de Maqueda, que en 1492 contaba con 281 familias de judíos, de los que consta que se convirtieron 68 , y en las relaciones de habilitados sólo aparecen en 1497 tres matrimonios, tres mujeres y un soltero que vivía en Talavera.

Para terminar, indicaré otra vía por donde se encauzaron los bienes de los judíos en 1492: el camino de América. Algunos autores aseguran que seis judíos acompañaron a Colón en su primer viaje ${ }^{18}$, y que en 1495 ya había judíos establecidos en varias islas del Caribe; es probable que las pepitas de oro que trajo Colón de La Española excitaran la predisposición comercial en el ánimo de los hebreos y muchos de ellos debieron de pasar a las Indias pese a las prohibiciones de los reyes, que temían que pudieran entorpecer la conversión de los indios a la fe.

A mediados del siglo XVI encontramos a gran número de judíos en el Nuevo Mundo, enriquecidos y plenamente asimilados a la sociedad española colonial.

${ }^{18}$ S. B. Liebman, Réquiem por los olvidados. Los judios españoles en América 14931825, Madrid 1984, pág. 13. 


\section{RESUMEN}

Para combatir las herejías de los judaizantes que tanto perturbaban a la sociedad española, los Reyes Católicos recurrieron a medidas de excepción que no fueron suficientes para conseguir el objetivo final de facilitar la unidad religiosa del reino. El edicto del 31 de marzo de 1492 puso fin a estos problemas decretando la supresión total del judaísmo. Se conservan algunos inventarios de bienes judaicos hechos en 1492 y listas de habilitaciones ante los receptores de la Inquisición, que nos dan idea del número de judíos y conversos en esa época y del estado de prosperidad o decadencia que tenían en las distintas ciudades.

\section{SUMMARY}

To combat the heresies of the Judaizers, so disturbing for the Spanish society, the Catholic Kings had recourse to certain special measures that proved insufficient to reach the final objective of the religious unity of the Kingdom. The edict of march 31 st 1492 put an end to those problems by declaring the total suppression of Judaism. Some inventories of Jewish properties listed in 1492 and some records of habilitaciones before the Receivers of the Inquisition have enabled us to know the number of Jewish and converts of that time, and their state of prosperity or decay in the different cities. 